\title{
In reply: Neuromuscular monitoring should be required when neuromuscular blocking drugs are used: Is it time to change the Canadian guidelines?
}

\author{
Gregory Dobson, MD • Richard N. Merchant, MD
}

Received: 11 March 2016/Accepted: 22 March 2016/Published online: 20 April 2016

(C) Canadian Anesthesiologists' Society 2016

We thank Dr. Hudson for his comments ${ }^{1}$ in response to publication of the 2016 edition of Guidelines to the Practice of Anesthesia. ${ }^{2}$ The Canadian Anesthesiologists Society (CAS) standards committee encourages and welcomes feedback related to the Guidelines.

Monitoring neuromuscular blockade has been on the agenda of the CAS standards committee for the past several years. Indeed, studies have documented an unacceptably high percentage of patients arriving in the postanesthesia care unit with a train of four (TOF) ratio of $<0.90$, which could result in significant adverse respiratory events and discomfort due to residual weakness. This issue was previously editorialized by Kopman, ${ }^{3}$ who stated that, "it is time for anesthesia professional organizations to finally draft evidence-based guidelines detailing how best to monitor and manage the perioperative administration of neuromuscular blocking drugs."

Although acknowledging the importance of residual weakness as an issue, the CAS standards committee has not yet been able to agree on the most appropriate way to introduce meaningful changes to the Guidelines that would accurately reflect the evidence on best practices and how they would add to the safety of our patients.

The current Guidelines' statement requiring that peripheral nerve stimulators be "exclusively available" when neuromuscular blocking drugs (NMBDs) are used

G. Dobson, MD $(\bowtie) \cdot$ R. N. Merchant, MD

Standards Committee, Canadian Anesthesiologists' Society,

Toronto, ON, Canada

e-mail: G.Dobson@Dal.Ca necessarily implies that the devices should be appropriately used. We agree that having them on the shelf or in a drawer in this setting contributes little to care! However, it may reasonably be considered not essential that a nerve stimulator be applied to every patient for every moment of every procedure during which NMBDs have been used, such as is now "required" for electrocardiography or pulse oximeter use. Nevertheless, we do believe that monitoring should be part of a broader strategy for the use of NMBDs that reflects attention to cautious NMBD dosing, the routine use and appropriate timing and dosing of cholinesterase inhibitors (and other reversal agents), and quantitative monitoring where available or qualitative monitoring with a current (mA) output display if quantitative monitoring is not available. Such detail includes an appreciation for the correct use (i.e., TOF vs double-burst stimulation $v s$ post-tetanic fade) and limitations of tactile qualitative monitoring due to technical problems with equipment as well as the potential limitations in our ability to interpret monitoring reliably and accurately. ${ }^{4}$ We must also recognize that, as with any device, quantitative monitors are not without problems. How to consider all of these factors and incorporate them into practice guidelines is a challenge.

Notably, many other professional anesthesiology organizations are also struggling with how to address these issues intelligently in guidelines. The Anesthesia Patient Safety Foundation has aggressively lobbied the American Society of Anesthesiologists to introduce stronger language in their guidelines. ${ }^{5}$ The CAS standards committee will continue to debate this issue vigorously with a view toward introducing meaningful changes into the Guidelines in the near future. We greatly appreciate this well-considered feedback. 
Conflicts of interest None declared.

Editorial responsibility This submission was handled by Dr. Hilary P. Grocott, Editor-in-Chief, Canadian Journal of Anesthesia.

\section{References}

1. Hudson RJ. Neuromuscular monitoring should be required when neuromuscular blocking drugs are used: Is it time to change the Canadian guidelines? Can J Anesth 2016; 63. DOI: 10.1007/ s12630-016-0639-5.

2. Merchant $R$, Chartrand D, Dain $S$, et al. Guidelines to the practice of anesthesia - revised edition 2016. Can J Anesth 2016; 63: 86-112.

3. Kopman AF. Managing neuromuscular block: where are the guidelines. Anesth Analg 2010; 111: 9-10.

4. Brull SJ, Murphy GS. Residual neuromuscular block: lessons unlearned. Part II: methods to reduce the risk of residual weakness. Anesth Analg 2010; 111: 129-40.

5. Stoelting $R K$. Residual drug-induced muscle weakness in the postoperative period: a patient safety issue. ASA Newsletter 2015; 79: 2 . 